\title{
Methodology for calculating the number of migratory birds in the territory of the wind farms of the Azov region using information and communication technology
}

\author{
Volodymyr Yeremieiev ${ }^{1,}$, Viacheslav Osadchyi ${ }^{1}$, Valerii Siokhin ${ }^{2}$, and Petro Gorlov ${ }^{2}$ \\ ${ }^{1}$ Bogdan Khmelnitsky Melitopol State Pedagogical University, Department of Informatics and Cybernetics, Melitopol, 72312, Ukraine \\ ${ }^{2}$ Bogdan Khmelnitsky Melitopol State Pedagogical University, Scientific and Training Center "Biodiversity", Melitopol, 72312, \\ Ukraine
}

\begin{abstract}
A methodology has been developed for calculating the number of migratory birds in the territory of wind power farms and the StatBirds1 program for statistical analysis of bird monitoring results at the wind power farm "Prymorsk-1" on the coast of the Sea of Azov in the Zaporizhzhya Region. In the process of accounting, the type and number of birds, the direction and type of flight (transit, feeding, demonstration), the height and length of the flight, the time each bird was in the observation areas were recorded. Monitoring was carried out during 24 days in 2017 at three observation areas in the territory of the wind farm.
\end{abstract}

\section{Introduction}

The capacity of Ukrainian wind power farms (WPF) has tenfold increased in the last 9 years [1]. Ukraine's energy strategy envisages the construction of new WPF, which will be able to produce at least $30 \%$ of all electricity from renewable energy sources by 2030 [2]. Taking into account all characteristics of the Pryazovskyi district, it should be stressed that this district has a number of advantages for the wind power farms construction in comparison with other regions of Ukraine. With a small area of the nature reserve fund, there is a small number of objects with environmental status, which predetermined the choice of a location for the placement of several highcapacity wind power farms (Botievo wind power farm, Prymorsk-1, Orlovsk wind power farm, Prymorsk-2).

Botievo wind power farm (capacity $100 \mathrm{~mW}$ ) is the first largest wind power farm in Ukraine. The "Prymorsk1" WPF with a capacity of $100 \mathrm{~mW}$ produces annually about 700 million kilowatt-hours of clean electricity [2]. This wind power farm is located on the shores of the Azov Sea, where several wind power farms with similar technical parameters are functioning and being built within the $60 \mathrm{~km}$ distance.

Current projects and developments in the field of renewable energy create new threats for birds [3]. At the UNO Climate Conference in Bonn, several researchers said that wind turbines are becoming a particular problem for migratory birds. The negative impact of wind power farms on ornithological complexes is greatly exaggerated, since wind power farms are point objects. Their danger to birds does not outweigh the danger of transmition lines, which, in comparison with wind power farms, occupy vast areas. The main threat to birds is caused by the possibility of their collision with the turbines in the case if the wind turbine units are located in places of their intensive movement. In the work [4] it is reported that the death rates of birds at the first small wind power farms are estimated at 2.1-63.8 individuals / a turbine / a year. The technical characteristics of the new generation of rotors provide a threefold negative impact reduction on the birds [5]. A large number of studies have been devoted to the study of the influence of wind power on ornithological complexes $[3 ; 6 ; 7 ; 8]$.

Wind power farms at the Azov Sea seaside are located in one of the most powerful migration routes in Eastern Europe - the Azov-Black Sea route, which predetermined the need to study the state of biodiversity in the territories of wind power farms $[9 ; 10]$. Project work to substantiate the impact of wind power farms on bird ornithological complexes within Prymorsk district of Zaporizhzhia region was carried out in 2011-2017 in accordance with the recommendations of the Scottish Natural Heritage Foundation [11]. On the basis of the obtained data, an analysis of the possibility of birds' death in the case of their collision with the rotor blades at the wind power farm Prymorsk-1 was carried out [9].

To estimate the possible number of collisions, information on the total number of collisions on a wind power farm is necessary. As a rule, it is necessary to process a considerable amount of information in order to monitor all this data, the analysis of which is not possible without the application of modern information and communication technologies. The purpose of this work is to develop and test the calculation method of the number of birds in the wind power farms territory. To achieve this goal, the following tasks had to be solved:

\footnotetext{
* Corresponding author: evs1938@gmail.com
} 
- to conduct the research on ornithological complexes at the observation sites using the recommendations of the Scottish Natural Heritage Foundation,

- to develop ICTs that provide statistical analysis of monitoring results,

- to create the mathematical model for determining the number of birds based on the observation results of bird migration,

- to test the calculation method on the example of monitoring results on the Prymorsk-1 wind power farm territory.

\section{Methods of gathering information and statistical processing of observation results}

\subsection{Physical characteristics of the territory of the Azov Wind power farms}

The wind power farms border with the sea of Azov on the south, and are surrounded by agricultural fields from the other sides. There is no natural tree vegetation on the WPF areas, buffer zones and adjacent territories. Tree species are found only in the form of artificially grown plants and along roads. The monitoring of bird migration on the territory of Prymorsk-1, the area of which is $10.1 \mathrm{~km}^{2}$, was carried out at three points of PS1, PS2, PS3 (Fig. 1), which by their natural parameters are close to the characteristics of the wind power farms and to the areas of all the power farms. The observation site areas of PS1, PS2, PS3 were, respectively, $0.50 \mathrm{~km}^{2}, 0.86 \mathrm{~km}^{2}$ and 1.23 $\mathrm{km}^{2}$. The total area of observation sites was $2.59 \mathrm{~km}^{2}$. The location of the PS provided a distance of no more than 2 $\mathrm{km}$ between the wind park and the observation point. The observation sector did not exceed $180^{\circ}$ for each PS.

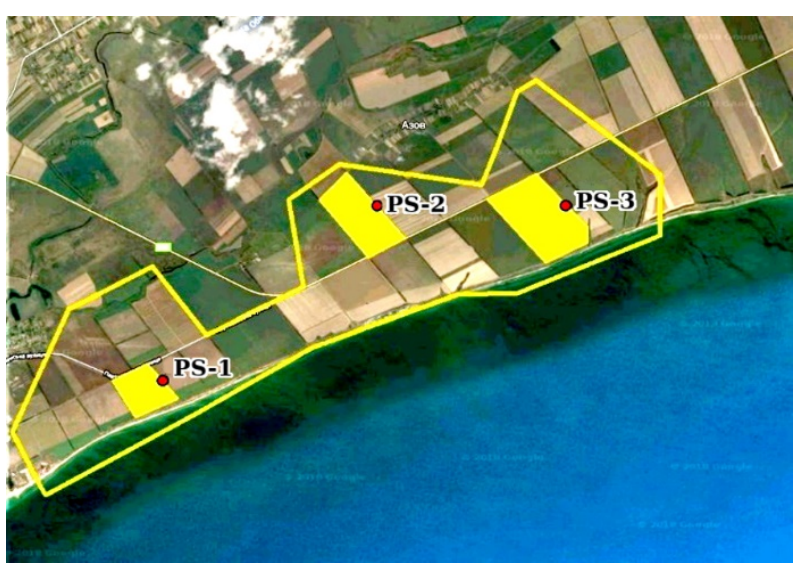

Fig. 1. Scheme of observation points location within the Prymorsk-1 wind park.

\subsection{Methods of observation}

Methodological developments in the study of ornithological situation in the territory of Prymorsk-1 were based on the recommendations of the Scottish Natural Heritage Foundation [11]. Measurements were made within 24 days in 2017. The duration of observations in different seasons is shown in Table 1.

Table 1. Duration of bird observation in different seasons in 2017.

\begin{tabular}{|l|l|c|c|c|}
\hline \multirow{2}{*}{ Observation cycle } & \multicolumn{4}{|c|}{ Duration of observation $\boldsymbol{T}$, hours } \\
\cline { 2 - 5 } & PS1 & PS2 & PS3 & $\sum \boldsymbol{T}_{\boldsymbol{i}}$ \\
\hline Spring migration & 24 & 24 & 24 & 72 \\
\hline Nesting & 42 & 42 & 42 & 126 \\
\hline Autumn migration & 36 & 36 & 36 & 108 \\
\hline Winter period & 42 & 42 & 42 & 126 \\
\hline Total & 144 & 144 & 144 & 432 \\
\hline
\end{tabular}

The flight altitude of each bird was recorded at the time of its appearance at the observation area. Subsequently, measurements and bird classification (into several groups) were carried out every 15 seconds. Considering the way of bird interaction with rotors it is possible to distinguish three groups:

- a group of birds with a flight altitude of up to the lower edge of the rotor $(48 \mathrm{~m})$,

- a group of birds with a flight altitude above the upper edge of the rotor $(182 \mathrm{~m})$,

- a group of birds at risk (RZ) of a collision with rotors at flight altitude between the lower and upper edges of the turbine.

Spring migration was studied in the first and third decades of March, as well as in the first decade of April. The nesting period was studied on April 25-28.04 and May 25-28.05. Autumn migration was studied in the second decade of September, the first and second decades of October and the first decade of November. Winter observation was combined with a wintering period in the second decade of January and a breakup period of wintering in the second decade of February.

The observations were carried out from 8.00 to 11.00 in the morning and from 13.30 to 16.30 in the evening with the determination of the type of birds, their number, direction of flight, type of flight (transit, feeding, demonstration), altitude and length of flight, the total time of the bird presence at the observation site, time spent at various heights.

\subsection{The tool base}

During the monitoring process, the following equipment was used: binoculars (20x); optical tubes OPTOLYTH 2060x80; optical tube VIXEN 20-60x100; optical tube VIXEN 20-60x80; a laser device for altitude determining NICON Forestry 550; devices for the coordinates determining GARMIN GPS MAP 78s.

\subsection{Software}

The primary processing of the observation results was carried out using the "WebBirds" application created by O. Annenkov [10]. The database management system (DBMS) "WebBirds" is a convenient tool for storing, accumulating, adjusting and processing the results of bird monitoring at the power farm. The DBMS is based on the tables of the recorded bird species, the number of individuals at various observation points, the territory of 
the wind power farm and other parameters of the study. The Web application allows you to create new records from mobile devices, add and update existing data on the number and types of birds, places of their seasonal placement, flight altitude, type and direction of migrations, as well as generate accounting results according to the specified parameters in a convenient form.

To conduct a statistical analysis of the observation results in this work, we created the StatBirds program in the Microsoft Visual Studio Community 2017 software development environment based on Windows Forms technology. The program presents the specific parameters that characterize the birds behavior on the territory of the Prymorsk-1 wind power farm: bird species, observation date and time, number (amount) of birds $n$, number of the observation area PS, flight direction of migrant birds, method (type) of presence at the observation site (transit, stern, demonstrative), the altitude and length of the trajectory in $\mathrm{m}$ on this area, the time spent by birds in the observation areas ( $t_{1}-$ the total time, $t_{2}-$ at the height up to the lower level of the wind wheel edge, $t_{3}-$ at the height between the lower and upper level of the wind wheel, $t_{4}-$ at the height over the upper level of the wind wheel edge), the coefficients $k_{1}, k_{2}, k_{3}, k_{4}$, which determine the birds activity at different heights. The values $k_{1}, k_{2}, k_{3}, k_{4}$ were calculated by the formula $k_{i}=t_{i} n_{i},(i=1,2,3,4)$.

\subsection{Methodology of the migrant number calculation}

Let the registration of birds of the $j$-th species be carried out at the observation site of PS with area $S_{0}$ during the time $T$. Denote the density of birds that are in the air per unit of time, as $n_{j}(t)$. The total number of birds in flight conditions $N_{j}$, per square unit, is equal to

$$
N_{j}=\left[\int_{0}^{T} n_{j}(t) d t\right] /\left(S_{0} T\right) .
$$

$T$ can be divided into smaller intervals $\tau_{i}=\tau_{1}, \tau_{2}, \tau_{3} \ldots$ with a bird density of $n_{i j}$. We require that the set of intervals $\{\tau i\}$ contain all the elements of the set $\left\{t_{i}\right\}$ that correspond to the time values $t_{i}$ of birds in the number $n_{i j}$ at this observation point. In this case, the value of the integral is estimated by

$$
N_{j}=\left[\int_{0}^{T} n_{j}(t) d t\right] /\left(S_{0} T\right) \approx\left(\sum_{i} n_{i j} \tau_{i}\right) /\left(S_{0} T\right) .
$$

The parameter $K_{j}=\sum n_{i j} t_{i j}$ in formula

characterizes the activity of birds presence at the PS area. If the parameters that determine the migration through the PS area and the adjacent region of square $S$ are the same, then the number of birds of the $j$-th species in flight condition in region $S$ is determined by the expression

$$
N_{j S}=S K_{j} /\left(S_{0} T\right)=S \sum n_{i j} t_{i j} /\left(S_{0} T\right) .
$$

The activity coefficient $K_{j}$ and formulas (1), (2) do not take into account birds on the ground, therefore, the total number of birds in flight condition and on the ground per square unit is

$$
N_{j}=\beta_{j} K_{j} /\left(S_{0} T\right)=\beta_{j} \sum n_{i j} t_{i j} /\left(S_{0} T\right)
$$

where the coefficient $\beta_{j} \geq 1$ depends on the type of bird, time of day, season and other indicators.

In this case, the total number of birds in region $\mathrm{S}$ in flight condition and on the ground is

$$
N_{j S}=\beta_{j} S K_{j} /\left(S_{0} T\right)=\beta_{j} S \sum n_{i j} t_{i j} /\left(S_{0} T\right),
$$

The value of $\beta_{j}$ varies over a wide range. It can be expected that for individuals that fly long distances in the spring and autumn seasons, the value of $\beta_{j}$ is about $1-5$. In the case of local birds that live in this area or constantly move from the habitat to the place of feeding, the value of $\beta_{j}$ is most likely in the range of 10-100.

The total density of birds of all species $N$ per square unit in accordance with formula (4) is

$$
N=\sum_{j} \beta_{j} K_{j} /\left(S_{0} T\right)=\sum_{j}\left(\beta_{j} \sum_{i} n_{i j} t_{i j}\right) /\left(S_{0} T\right) .
$$

Knowing the density (5), we can estimate the total number of individuals of all species $N_{s}$ on the territory $S$ adjacent to the wind park, according to the formula

$$
N_{S}=S \sum_{j} \beta_{j} K_{j} /\left(S_{0} T\right)=S \sum_{j}\left(\beta_{j} \sum_{i} n_{i j} t_{i j}\right) /\left(S_{0} T\right) .
$$

\section{Bird monitoring results at observation points and statistical data processing}

\subsection{Measurement results}

In 2017, 5923 birds of 45 species were recorded, 2061 of which were recorded at PS1, 1824 at PS2 and 2038 at PS3. Most of them were in the spring (50\%) and autumn (35\%) periods. The primary processing of the results was carried out using the WEB application "WebBirds" [10]. An example of registration of birds in paragraph PS3, which were recorded during one day on $03 / 13 / 2017$, is presented in part of the table 2, where the following designations are used: species of birds (Species of birds), time of day $(M-$ morning from 8.00 to $11.00, E v$ - evening from 13.30 to 16.30), number of birds of the observed species $(n)$, direction of flight $\operatorname{Dir}(N-$ North, $S$ - South, $E-$ East, $W-$ West), type flight - Type ( $T r$ - transit, $F$ - feeding, Dem demo), height $(H)$ and flight length $(L)$, total time spent by individuals $t_{1}$ in point of registration, the time spent by individuals at a height less than the level of the lower edge of the rotor $H_{1}=48 \mathrm{~m}\left(t_{2}\right)$, the time spent by individuals $t_{4}$ at a height greater than the level of the upper edge of the rotor $H_{2}=182 \mathrm{~m}$, the time spent by individuals in RZ $t_{3}$ at the height between $H_{1}$ and $H_{2}$, the total activity coefficients of birds presence at the observation point $K_{1}=t_{1} n$ and in RZ $K_{3}=t_{3} n$. 
According to the table 2, on the PS3 area, within one day, March 13, 2017, 101 individuals of 9 species were recorded. 71 birds were observed in the morning time, and $30-$ in the evening. The greatest activity is related to the species Sturnus vulgaris (37 individuals). Most of the birds were found at heights lower than the lower boundary of the RZ, i.e. below $48 \mathrm{~m}$. One Circus aeruginosus bird was observed in the RZ at the height of $60 \mathrm{~m}$ for $34 \mathrm{~s}$. Birds did not fly above the upper boundary of the RZ on this day. The activity coefficient of birds $K_{1}$ for all heights on the PS3 site within one day 03.13.2017 is 2570 s., that is two orders of higher than the coefficient value $K_{3}=34 \mathrm{~s}$, that is related to the RZ. Similar results were obtained at all areas.

Table 2. Monitoring results at PS3 area within one day 03.13.2017

\begin{tabular}{|c|c|c|c|c|c|c|c|c|c|c|c|c|c|}
\hline No & Species of birds & $\mathrm{M} / \mathrm{Ev}$ & $N$ & Dir & Type & $H, \mathrm{M}$ & $L, \mathrm{M}$ & $\mid t_{1}, \mathrm{~s}$ & $t_{2, \mathrm{~S}}$ & $t_{3}, \mathrm{~s}$ & $t_{4}, \mathrm{~S}$ & $K_{1}, \mathrm{~s}$ & $K_{3, \mathrm{~s}}$ \\
\hline 1 & Circus aeruginosus & \multirow{7}{*}{ M } & 1 & $\mathrm{~N}$ & $\mathrm{~T}$ & 60 & 800 & 44 & 10 & 34 & 0 & 44 & 34 \\
\hline 2 & Sturnus vulgaris & & 37 & SE & $\mathrm{K}$ & 5 & 550 & 30 & 30 & 0 & 0 & 1110 & 0 \\
\hline 3 & Corvus cornix & & 2 & $E$ & $\mathrm{~K}$ & 7 & 550 & 30 & 30 & 0 & 0 & 60 & 0 \\
\hline 4 & Larus ridibundus & & 6 & $\mathrm{E}$ & $\mathrm{T}$ & 10 & 830 & 46 & 46 & 0 & 0 & 276 & 0 \\
\hline 5 & Corvus frugilegus & & 5 & $\mathrm{NW}$ & K & 7 & 650 & 36 & 36 & 0 & 0 & 180 & 0 \\
\hline 6 & Larus ridibundus & & 10 & SW & $\mathrm{T}$ & 15 & 800 & 44 & 44 & 0 & 0 & 440 & 0 \\
\hline 7 & Larus ridibundus & & 10 & $\mathrm{~W}$ & $\mathrm{~T}$ & 15 & 830 & 46 & 46 & 0 & 0 & 460 & 0 \\
\hline \multicolumn{3}{|c|}{ The amount of measurements in the morning } & 71 & & & & & & & & & 2570 & 34 \\
\hline 1 & Falco tinnunculus & \multirow{8}{*}{ Ev } & 1 & $\mathrm{NE}$ & K & 25 & 700 & 39 & 39 & 0 & 0 & 39 & 0 \\
\hline 2 & Streptop.decaocto & & 2 & $\mathrm{~N}$ & K & 5 & 400 & 22 & 22 & 0 & 0 & 44 & 0 \\
\hline 3 & Larus ridibundus & & 7 & $\mathrm{E}$ & $\mathrm{T}$ & 10 & 780 & 43 & 43 & 0 & 0 & 301 & 0 \\
\hline 4 & Larus ridibundus & & 3 & $\mathrm{E}$ & $\mathrm{T}$ & 15 & 780 & 43 & 43 & 0 & 0 & 129 & 0 \\
\hline 5 & Circus aeruginosus & & 1 & $\mathrm{NW}$ & K & 30 & 830 & 46 & 46 & 0 & 0 & 46 & 0 \\
\hline 6 & Larus cachinnans & & 3 & $\mathrm{~S}$ & $\mathrm{~T}$ & 10 & 480 & 27 & 27 & 0 & 0 & 81 & 0 \\
\hline 7 & Corvus frugilegus & & 12 & $\mathrm{~N}$ & K & 7 & 550 & 30 & 30 & 0 & 0 & 360 & 0 \\
\hline 8 & Falco tinnunculus & & 1 & $\mathrm{~W}$ & $\mathrm{~K}$ & 25 & 700 & 39 & 39 & 0 & 0 & 39 & 0 \\
\hline \multicolumn{3}{|c|}{ The amount of measurements in the evening } & 30 & & & & & & & & & 1039 & 0 \\
\hline \multicolumn{3}{|c|}{ Total number of measurements in the morning and evening } & 101 & & & & & & & & & 3609 & 34 \\
\hline
\end{tabular}

The vast majority of birds in winter period $(86.9 \%)$ were recorded at heights of up to $10 \mathrm{~m} .13 .1 \%$ of individuals were in the range of 10-50 m. No birds were found in the risk zone of $51-150 \mathrm{~m}$. The main migration vectors were the east $(31.21 \%)$ and the southeast $(23.76 \%)$. The number of migrants in the southern (11.83\%) and north-eastern (11.73\%) directions was two times lower. For each of the other areas, about $6 \%$ were taken into account, Fig. 2.

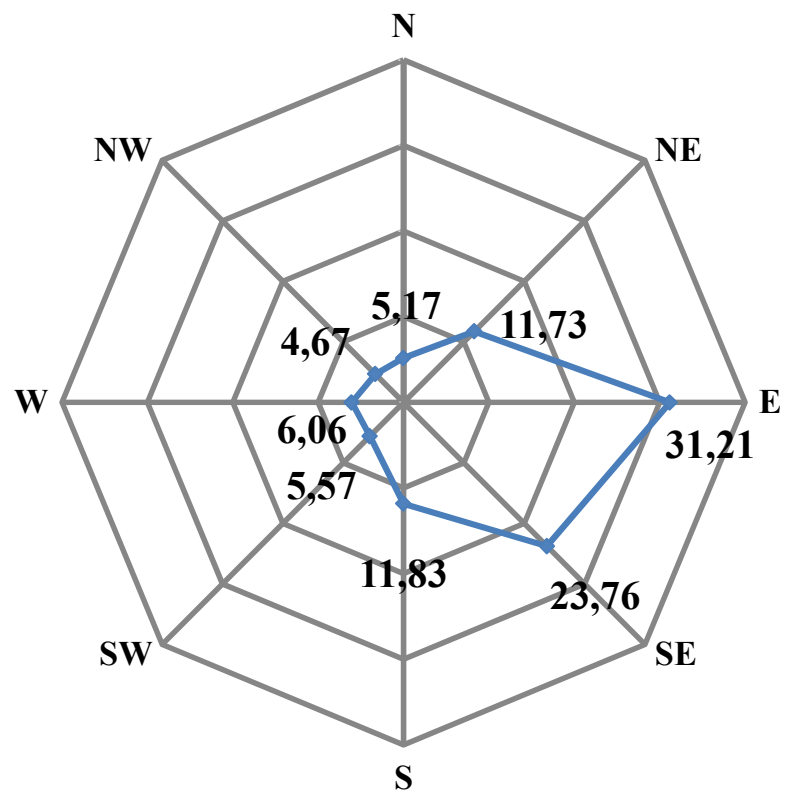

Fig. 2. Directions of bird movements in winter period (quantity in \%).
In the spring migration period, $98.4 \%$ of birds were recorded at the safe heights of up to $50 \mathrm{~m} .1 .6 \%$ of all recorded birds were found in the risk zone. About half of the birds $(67.9 \%)$ flew to the northwest, north, northeast and east. Additional flight directions were the southwest $(12.1 \%)$ and the southeast $(9.4 \%)$, Fig. 3.

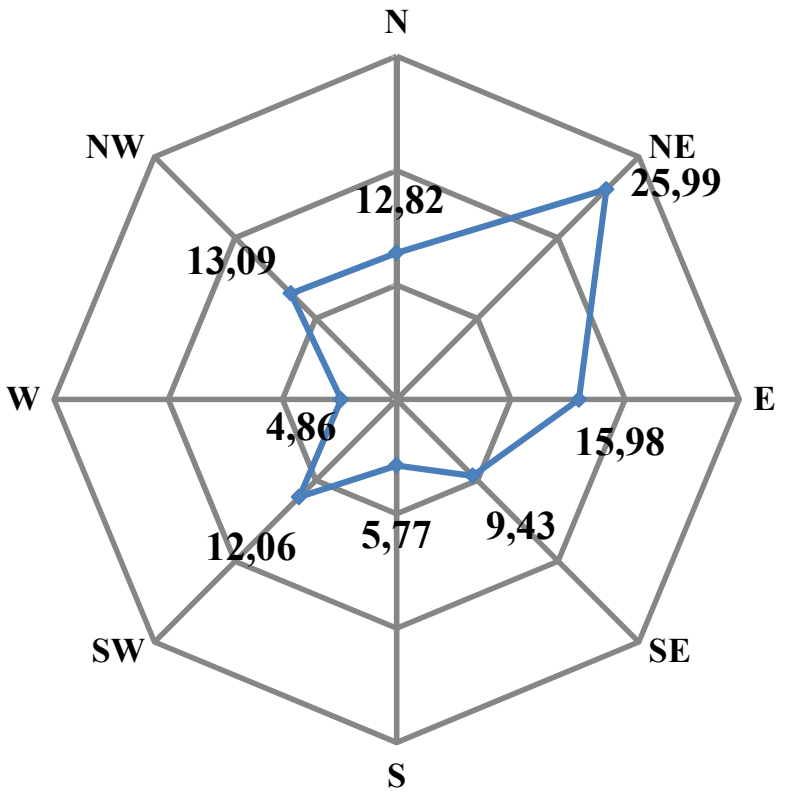

Fig. 3. Directions of spring migration of birds (quantity in \%).

Altitudinal movements of birds in the nesting period were distributed as follows. All birds at heights of less than $50 \mathrm{~m}$ were recorded. The vast majority of birds were observed in the surface altitude range up to $10 \mathrm{~m}(92.4 \%)$. This nature of the altitudinal distribution is explained by 
the fact that most birds at this time of year are in their nests. The main directions were the north, the northeast, the east (only 55.1\%) and the southeast (22.0\%), Fig. 4.

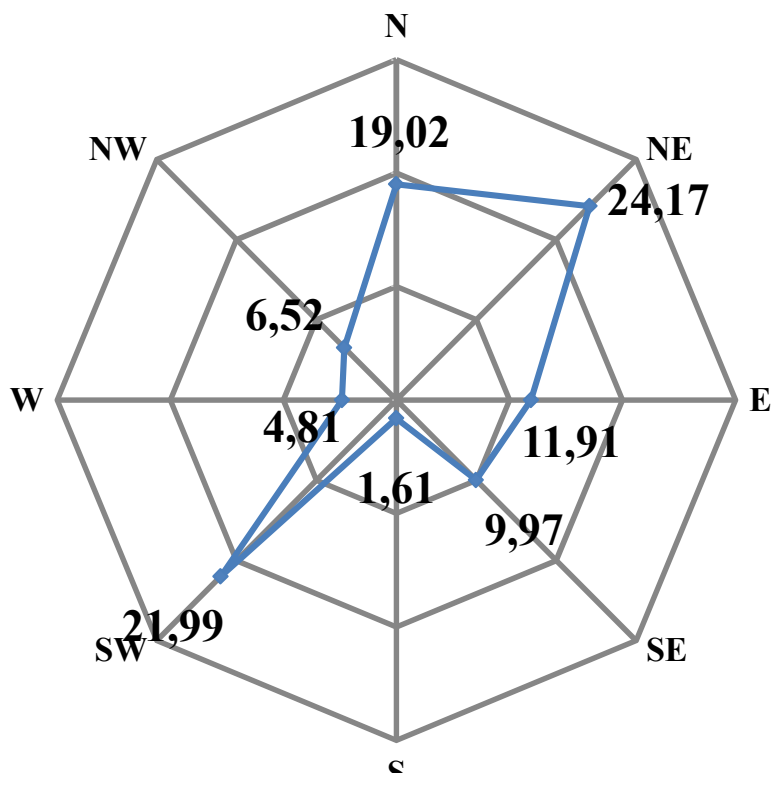

Fig. 4. Direction of bird flight in the nesting period (quantity in $\%$ ).

Observations of autumn migration showed that $99.4 \%$ were at safe altitudes. In the risk zone, 6 birds were recorded $(0.6 \%)$. The main directions of migration were the northeast, the east and the southeast $(68.8 \%)$, Fig. 5.

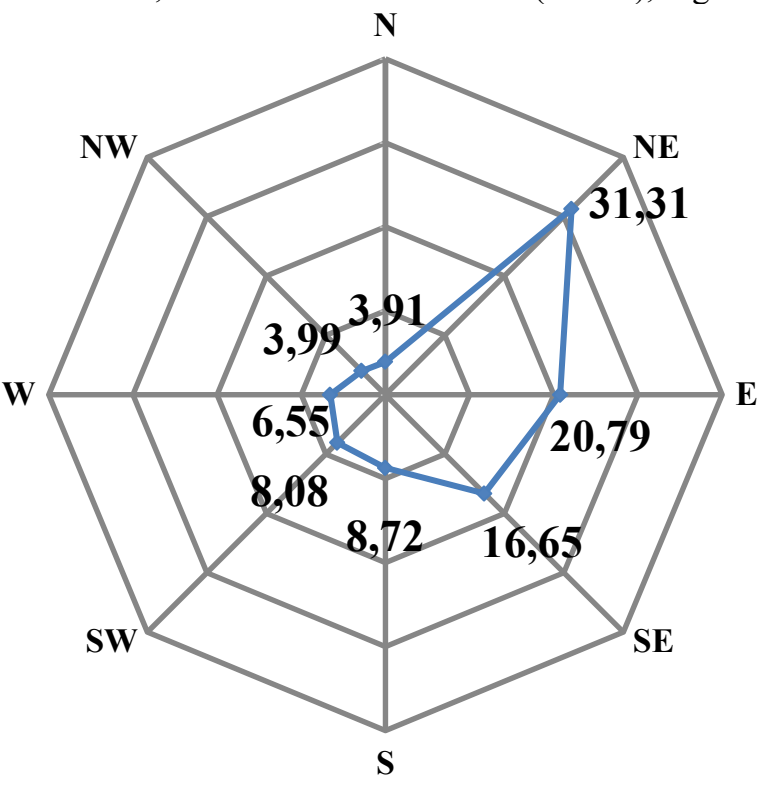

Fig. 5. Directions of autumn bird migration (quantity in \%).

Statistical processing of bird monitoring results was carried out using the StatBirds program. The number of registered birds of various species in 2017 in the most dangerous altitude range (RZ) is given in table 3 . The general coefficient of activity $K_{3}$ for them turned out to be equal to $K_{3}=2196 \mathrm{~s}$, which is two orders less than the value $K_{1}=170048 \mathrm{~s}$, which relates to the entire ornithocomplex.

It follows from the Table 3 that 72 birds were found in the RZ at altitudes between $48 \mathrm{~m}$ and $182 \mathrm{~m}$. Most of them belong to Larus ridibundus (43 birds) and Merops apiaster (15 birds). The number of individuals for Buteo buteo and Circus aeruginosus was 5 and 9, respectively.

Table 3. Bird monitoring results in $\mathrm{RZ}$ on all observation areas.

\begin{tabular}{|l|l|l|c|c|}
\hline Bird species & Season & $\begin{array}{l}\text { Area number(s): the } \\
\text { number of birds } n\end{array}$ & $t, \mathrm{~s}$ & $K_{3}$ \\
\hline \multirow{5}{*}{ Buteo buteo } & Summer & $1,2,3: 0$ & 0 & 0 \\
& Autumn & $1: 1,1$ & 36,7 & 43 \\
& Autumn & $2: 1,1$ & 51,30 & 81 \\
& Autumn & $3: 1$ & 18 & 18 \\
& Winter & $1,2,3: 0$ & 0 & 0 \\
\hline \multirow{5}{*}{ Circus } & Spring & $1: 1,1$, & 51,19 & 70 \\
aeruginosus & Spring & $2: 1,1$ & 18,40 & 58 \\
& Spring & $3: 1,1$ & 34,40 & 74 \\
& Summer & $1,2,3: 0$ & 0 & 0 \\
& Autumn & $1: 1$ & 25 & 25 \\
& Autumn & $2: 1$ & 30 & 30 \\
Merops & Autumn & $3: 1$ & 72 & 72 \\
apiaster & Winter & $1,2,3: 0$ & 0 & 0 \\
\hline \multirow{5}{*}{ Larus } & Spring & $3: 15$ & 33 & 495 \\
ridibundus & Summer & $1,2,3: 0$ & 0 & 0 \\
& Autumn & $1,2,3: 0$ & 0 & 0 \\
& Winter & $1,2,3: 0$ & 0 & 0 \\
\hline & Spring & $1: 5,7,3,8$ & 42,$25 ;$ & 650 \\
& Spring & $3: 7$ & 19,26 & \\
& Summer & $1,2,3: 0$ & 42 & 294 \\
& Autumn & $3: 7,6$ & 0 & 0 \\
& Winter & $1,2,3: 0$ & 28,15 & 286 \\
\hline
\end{tabular}

The average density of the total number of birds in flight condition $N$ and on the ground per square unit is determined by the formula (5). The parameter $\beta_{j}$ in this formula depends on the type of individual, time of day, season, terrain characteristics, etc. Let's suppose that the average value of $\beta_{j}$ is 30 .

In this case, the total number of birds in flight condition and on the ground on three areas PS1, PS2, PS3 will be 4.8 . The characteristics of the observation points and the surrounding areas of the power farms are identical. The coastal area, where four wind power farms are located, is approximately $10^{3} \mathrm{~km}^{2}$. The total number of birds in this zone and at the Prymorsk-1 power farm according to formula (6) is 18.8 and 4800 , respectively.

\subsection{Distribution of birds in flight condition by monitoring areas}

The density of birds at different areas of observation is determined by formula (5), where the coefficient $\beta_{j}$ should be set equal to 1 . The calculation results are presented in the table 4 . When compiling the table 4 the following designations were accepted:

$N$ is the estimated value of the number of birds in flight condition (in brackets is the average value of the number of recorded birds a, referred to one day of registration on the area of $1 \mathrm{~km}^{2}$ ),

$N_{m}, N_{E v}, a_{M}, a_{E v}$ - the same separately for morning $M$ and evening $E v$ observations,

$N_{T r}, N_{S t}, a_{T r}, a_{S t}$ - the same for birds with different types of flight (transit $T r$ and feeding $S t$, respectively), 
$N_{E}, N_{S E}, a_{E}, a_{S E}$ - the same for birds per day, with the preferred direction of migration in the eastern $E$ and the southeast $S E$ directions, respectively.

From the table 4 it is obvious that the average number of birds a, recorded in various cases, is three orders of magnitude greater than the number of birds $N$ that are only in-flight condition.

Table 4. The calculated total number of birds in flight condition $N_{F}$ and the number of recorded birds $a$ (in brackets) when measured per $1 \mathrm{~km}^{2}$.

\begin{tabular}{|c|c|c|c|}
\hline & PS1 & PS2 & PS3 \\
\hline \multirow{2}{*}{$N(a)$} & 172 & 88 & 69 \\
& $(0.366)$ & $(0.149)$ & $(0.083)$ \\
\hline \multirow{2}{*}{$N_{M}\left(a_{M}\right)$} & 85 & 45 & 38 \\
& $(0.179)$ & $(0.075)$ & $(0.047)$ \\
\hline$N_{E v}\left(a_{E v}\right)$ & 87 & 44 & 31 \\
& $(0.187)$ & $(0.074)$ & $(0.036)$ \\
\hline$N_{S t}\left(a_{S t}\right)$ & 63.5 & 34.2 & 48.5 \\
& $(0.127)$ & $(0.058)$ & $(0.026)$ \\
\hline \multirow{2}{*}{$N_{T r}\left(a_{T r}\right)$} & 108.5 & 54 & 47 \\
& $(0.239)$ & $(0.091)$ & $(0.057)$ \\
\hline \multirow{2}{*}{$N_{S}\left(a_{S}\right)$} & 48 & 19.5 & 20.6 \\
& $(0.084)$ & $(0.030)$ & $(0.026)$ \\
\hline \multirow{2}{*}{$N_{S E}\left(a_{S E}\right)$} & 32 & 17.7 & 11.9 \\
& $(0.067)$ & $(0.032)$ & $(0.012)$ \\
\hline
\end{tabular}

Morning and evening measurements do not differ greatly from each other. Most of the birds flew in transit, while the eastern and south-eastern directions of migration were the main ones. The activity of birds at different areas of observation was different. The highest activity was recorded at PS1. There is a linear correlation between the parameters $N$ and $a$

$$
N=A+B a
$$

The table 5 presents the correlation coefficients $K_{N a}$, between the values of $N$ and $a$, calculated for each observation area and in general for all areas using the formula

$$
K_{N a}=\frac{\sum N_{i} a_{i}-n N_{a} a_{a}}{n s_{N} s_{a}}
$$

where $N_{a}, a_{a}, s_{N}, s_{a}$ are equal

$$
\begin{gathered}
N_{a}=\sum N_{i} / n \quad a_{a}=\sum a_{i} / n, \\
s_{N}=\sqrt{\sum\left(N_{i}-N_{a}\right)^{2} / n}, s_{a}=\sqrt{\sum\left(a_{i}-a_{a}\right)^{2} / n} .
\end{gathered}
$$

The values of the coefficients $A$ and $B$ were calculated by the formulas

$$
B=s_{N} K N_{a} / s_{a}, A=N_{a}-B a_{a} .
$$

The significance of the correlation coefficients for $n-2$ degrees of freedom was determined using Student's $T$-criterion. The calculated values of this criterion for observation areas PS1, PS2, and PS3 were 31.20, 59.83, and 3.81, respectively, which exceeds the critical value $T_{c r}=2.01$ and, therefore, allows to present the correlation dependence in the form of $a$ regression equation (7). The correctness of the use of regression equations is confirmed by a small standard deviation $s$ of the values of $N$ from table 5 from the values calculated using the correlation equations. In the most disadvantageous case, the value of $s$ is about 0.021 .

Table 5. Correlation coefficients $K_{N a}$, critical value $T_{k r}$, regression coefficients $A$ and $B$ in equation (7) per $1 \mathrm{~km}^{2}$ and standard deviation $s$ of the calculation results by formula (7) from the values calculated by formula (5) for individual areas and on average by all areas $\Sigma$.

\begin{tabular}{|c|c|c|c|c|}
\hline & PS1 & PS2 & PS3 & $\Sigma$ \\
\hline$K_{N a}$ & 0.997 & 0.999 & 0.863 & 0.970 \\
\hline$T$ & 31.20 & 59.83 & 3.81 & 17.35 \\
\hline$T_{k r}$ & 2.01 & 2.01 & 2.01 & 1.73 \\
\hline$A$ & -0.010 & -0.00058 & 0.00028 & -0.0271 \\
\hline$B$ & 0.00221 & 0.00170 & 0.00107 & 0.00225 \\
\hline$S$ & 0.0068 & 0.0014 & 0.011 & 0.021 \\
\hline
\end{tabular}

\subsection{The distribution of birds by seasons}

Analysis of the distribution of birds by seasons was carried out using observational data in winter, in the spring migration period, in the nesting period and in the autumn migration period, shown in Fig. 2-5. The calculations took into account all species of birds recorded in the morning and evening times at all three areas, flying at all altitudes. The correlation coefficient $K_{N a}$ between the calculated number of birds in flight condition and the measurement results in this case is 0.97 , Student's criterion at 5\% significance level for $n-2$ degrees of freedom $T=5.94$, critical value $T_{c r}=2.92$. Since $T>T_{c r}$, the correlation dependence $N(a)$ is significant and the regression equation (7) can be constructed using formulas (10) in the form

$$
N=0.037+0.00092 a \text {. }
$$

Comparative data obtained by formulas (5) and (11) are presented in table 6 .

Table 6. The average number of recorded birds $a$ in flight condition measured per day and $1 \mathrm{~km}^{2}$ and the results of calculating the number of birds $N$ by the formula (5) and $N_{R e g r}$, by the formula (11).

\begin{tabular}{|l|c|c|c|c|}
\hline & $\begin{array}{c}\text { Winter } \\
\text { period }\end{array}$ & $\begin{array}{c}\text { Spring } \\
\text { migration }\end{array}$ & Nesting & $\begin{array}{c}\text { Autumn } \\
\text { migration }\end{array}$ \\
\hline$a$ & 99 & 139 & 59 & 130 \\
\hline$K=\sum n_{i} t_{i}, c$ & 11695 & 26040 & 11607 & 22160 \\
\hline$N$, formula (5) & 0.135 & 0.172 & 0.090 & 0.147 \\
\hline$N_{\text {Regr }}$, formula (10) & 0.129 & 0.166 & 0.092 & 0.157 \\
\hline
\end{tabular}

In this case, the standard deviation of the experimental values from the values calculated using the regression equation is 0.0069 .

\subsection{Resume}

The Azov-Black Sea coast of Ukraine contains unique steppe plant habitats with numerous populations of migrating birds on the Eurasian scale, therefore the state of biodiversity monitoring on the territory of the wind 
power farm is of great importance. The movement of birds in different phases of their life cycle (nesting period, spring and autumn migration, wintering) are significantly different from each other. The largest number of birds were recorded during spring and autumn migrations. The used estimate of the number of migratory birds and their total number at a given time implies monitoring of the observation sites in accordance with the recommendations of the Scottish Natural Heritage Foundation [11]. It is based on the use of formulas (1) - (11), in which the main parameter is the coefficient $K=\sum n_{i} t_{i}$.

The value $K$ characterizes the activity of birds presence on the area. Calculation of the $K$ value allows us to estimate the average number of migrating birds $N$ at $a$ given moment of time, not only on this area, but also in the territory adjacent to it.

From general considerations, it is clear that the value of $N$ depends on the movement speed of individuals, their flight trajectory and many other parameters. A statistical analysis of the results of monitoring the territory of the Prymorsk-1 wind power farm showed that in reality it is determined by one integral characteristic by coefficient $K$. The correlation coefficient between the average number of migrants that are at the observation point and the registered number of birds $a$ crossing this area is estimated by value of 0.97 . Moreover, the Student's criterion, which determines the significance of the correlation coefficient, is at least 5.9, which is several times higher than the critical value.

In conclusion, we will carry out a general analysis by combining all the observation results presented in Table (4) - (6). The resulting regression equation has the form

$$
N=-0.0105+0.00182 a \text {. }
$$

In this case, the correlation coefficient between the number of birds in the air and the counting results is 0.91 . The Student's criterion, which determines the significance of the correlation coefficient, is about 10.5 , which is more than six times the tabular value of 1.71. A graphical interpretation of the dependence of $N$ on $a$ is shown in Fig. 6. The straight line in this figure is constructed using the regression equation (12), and the points correspond to experimental data.

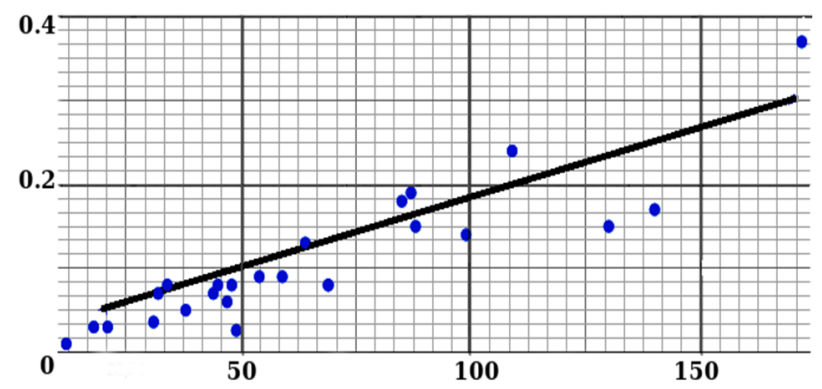

Fig. 6. The correlation dependence between the measured number of birds a and the number of individuals $N$ currently in flight condition.

The Fig. 6 shows that the experimental points are generally consistent with the regression equation (12). The inaccuracy of using formulas (3) and (5) for determining the number of birds per square unit depends only on the error in determining the coefficient of birds activity $K=\sum n_{i} t_{i}$. This inaccuracy does not exceed 3-5 seconds, which can lead to an error in calculating the parameter $K$ by no more than $5-10 \%$. The main reason for the scatter of points in Fig. 6 is caused not so much by the error in determining the parameter $K$ as by the statistical spread of the recorded data results depending on the season and the selected observation point for accounting.

\section{Conclusions}

In the work, the behavior of bird ornithological complexes in the territory of the Prymorsk-1 wind power farm in 2017 was studied using the recommendations of the Scottish Natural Heritage Foundation. During the observation, 5923 birds of 45 species were recorded. A statistical analysis of the observation results was carried out and a group of birds at risk zone of collision with turbines of a wind power farm was identified (Larus ridibundus - 43 birds, Merops apiaster - 15 birds, Buteo buteo - 5 birds and Circus aeruginosus - 9 birds).

The StatBirds program was developed for statistical analysis of the observation results and a mathematical model for calculating the number of birds in flight condition and on the ground. The number of birds in the territory of the wind power farm was estimated basing on the monitoring results in the winter, spring and autumn periods. According to the calculated data, the average number of birds of all species on the territory of the Prymorsk-1 wind power farm is about 18.8 individuals. Correlation dependencies between the number of individuals in flight state and the number of birds recorded at the observation areas were found.

\section{References}

1. Wind Power: Present and Future (2018), https://ridentenergy.ua/en/wind-power-present-andfuture/. Accessed 10 Jan 2020

2. Wind power energy in Ukraine: 7 most powerful wind power farms (2019), https://shotam.info/vitrova-enerhetyka-v-ukraini-7naypotuzhnishykh-stantsiy/. Accessed 10 Jan 2020

3. R.G. Powlesland, Impacts of wind power farms on birds: a review. Science for conservation 289 (Department of Conservation, Wellington, New Zealand, 2009)

4. J.E. Winkelman, De invloed van de Sepproefwindcentrale te Oosterbierum (Fr.) op vogels, 1: aanvaringsslachtoffers. RIN-rapport 92/2 (DLOInstituut voor Bos- en Natuuronderzoek, Arnhem, Netherlands, 1992)

5. K.L. Krijgsveld, K. Akershoek, F. Schenk, F. Dijk, S. Dirksen, Collision risk of birds with modern large wind turbines. Ardea 97(3), 357-366 (2009)

6. F. Liechti, J. Guélat, S. Commenda-Zehnder, Modelling the spatial concentrations of bird 
migration to assess conflicts with wind turbines. Biological Conservation 162, 24-32 (2013)

7. A.W.J. Bicknell, E.V. Sheehan, B.J. Godley, P.D. Doherty, M.J. Witt, Assessing the impact of introduced infrastructure at sea with cameras: A case study for spatial scale, time and statistical power. Marine Environmental Research 147, 126-137 (2019). doi:10.1016/j.marenvres.2019.04.007

8. Sh. Wang, S. Wang, P. Smith, Ecological impacts of wind power farms on birds: Questions, hypotheses, and research needs. Renewable and Sustainable Energy Reviews 44, 599-607 (2015). doi:10.1016/j.rser.2015.01.031

9. V. Osadchyi, V. Siokhin, P. Gorlov, V. Yeremieiev, K. Osadcha, Development of the information system for forecasting collision between birds and wind power farms. Eastern-European Journal of Enterprise Technologies 4/2(100), 29-40 (2019). doi:10.15587/1729-4061.2019.1743

10. O.B. Annenkov, Methods of using the WebBirds Web application for monitoring seasonal ornithological complexes and computer simulation of the impact assessment of wind farms. Melitopol, 93-107 (2014)

11. Recommended bird survey methods to inform impact assessment of onshore wind power farms (2014), https://www.nature.scot/sites/default/files/2017-

09/Guidance $\% 20$ note $\% 20$ -

\%20Recommended\%20bird\%20survey\%20methods $\% 20$ to $\% 20$ inform $\% 20$ impact $\% 20$ assessment $\% 20$ of $\% 20$ onshore\%20windfarms.pdf. Accessed 15 Jan 2020 